\title{
FDTD COMPUTATION FOR SAR INDUCED IN HUMAN HEAD DUE TO EXPOSURE TO EMF FROM MOBILE PHONE
}

\author{
Ashraf A. Aly ${ }^{1}$ and Melinda Piket-May ${ }^{2}$ \\ ${ }^{1}$ Department of Information Technology, Al Khawarizmi College, UAE \\ ${ }^{2}$ Departement of Electrical and Computer Engineering, \\ University of Colorado at Boulder, USA
}

\begin{abstract}
This aim of this paper is to investigate the specific absorption rate (SAR) distribution in a human head by using the finite-difference time-domain (FDTD) calculations, due to exposure to EMF radiation from a mobile phone at frequencies $900 \mathrm{MHz}$. Mobile Phone model with a $\lambda / 2$ monopole antenna and a hand head phone model dimensions are $100 \mathrm{~mm} \times 50 \mathrm{~mm} \times 20 \mathrm{~mm}$. The head model used is a sphere with a diameter of $18 \mathrm{~cm}$. The FDTD grid size used in the computation was $2.5 \mathrm{~mm}$. The distance between the antenna and head was $5 \mathrm{~mm}$. To simplify the FDTD simulation, the SAR in the head was calculated without the effect of the human body. It was found that the SAR induced in the head decreases with the distance from the radiating source.
\end{abstract}

\section{KEYWORDS}

Specific Absorption Rate, Finite-Difference Time-Domain, Mobile Phone

\section{INTRODUCTION}

After the increase in the use of mobile phones in the recent years, concerns have been raised about the biological effect of the exposure to the mobile phones radiofrequency electromagnetic radiation [22][23][24][25][26]. The effect translates into a significant public health problem. In recent years, the public concern about the possible health hazards of radio frequency (RF) field exposure from mobile phones has increased and initiated many studies on the possible adverse consequences on human health [25][26]. The possible interaction between the radio frequency (RF) electromagnetic radiation and its biological effects on human tissues particularly on the brain, cancer, and the human immune system have been investigated. The risk of exposure to electromagnetic field was first highlighted and publicized in the late 1970s by Colorado study [27] that linked magnetic field exposure from power lines to the possible development of child leukemia.

The importance of some studies, such as; the study by Satter et al.,(1999) was done on human patients, where, the rest of the studies used rats as a case control. Some of the advantages of other studies such as Makar et al.(2005), is the use of microwave therapy to reduce toxic effects of chemotherapy during the cancer treatment. This is a good addition to chemotherapy treatments even if the mechanism of the radiation effect is unclear. On the other hand, many research studies 
indicate link between EMF radiation and negative biological effects. The conclusion on the risk, specially for brain tumors associated with the use of cell phone have been mostly with an insufficiently long latency period (Phillips, 2006), however, the studies showed a somewhat increase risk for shorter latency periods. Long term (10 years or more) studies showed a statistically significant increase risk on the exposure to EMF radiation (Christensen, 2006). The study by Hardell et al., (2006) indicated that significant increase of risk of DNA damage was found with the use of analogue phones and the analysis showed less risk with digital phones. Moreover, many studies indicated another biological effects such as; blood-brain barrier (BBB) permeability function, sleep problems (Hung, 2000), immunity system function (Aly, 2008). The biological effects are uncertain as the biophysical mechanisms behind their occurrence are unknown. Finally, some research studies indicated no clear association was found between the exposure to the EMF radiation and biological effects.

The amount of RF generated by cell phone is usually depends on the number of base stations around the area, the cell phone network traffic, and on how far the cell phone from base stations. The amount of the power which sent from a base station could vary from cell phone to another one even within the same area, depends on the interfering from obstacles such as buildings and trees [28]. Although, cell phones are designed to operate at power levels below a threshold for known thermal effects, radio frequency radiation could produce other kinds of effects, called biological effects.

Due to the radiation effect, are needed to estimate the absorbed energy and its distribution inside the body. A dosimetry quantity that is widely adopted for microwaves is the Specific Absorption Rate (SAR). SAR is defined as the time derivative of the incremental energy, absorbed by or dissipated in an incremental mass contained in a volume element of a given density. SAR is expressed in the unit watt per kilogram $\left(\mathrm{W} \mathrm{kg}^{-1}\right)$. Numerical calculations, based upon coupling from handsets to an anatomically realistic numerical phantom of the head have been performed. Such calculations have shown that, during normal operation, a radiated power of $1 \mathrm{~W}$ gives rise to a maximum SAR of $2.1 \mathrm{~W} \mathrm{~kg}^{-1}$ at $900 \mathrm{MHz}$ and $3.0 \mathrm{~W} \mathrm{~kg}^{-1}$ at $1.8 \mathrm{GHz}$ averaged over any $10 \mathrm{~g}$ of tissue. Typical handset powers are $0.6 \mathrm{~W}$.

The satellite network communication systems recently designed to enable communication with sites not easily reachable with ground networks. Small itinerant units and hand-held sets identical to the current mobile telephones will be take part. Higher power classes in these special cases can be visualize.

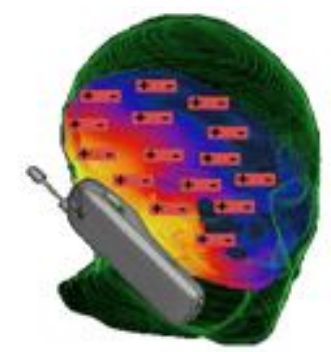

Fig. 1. Model of the cellular phone phantom. 
Digital mobile telephones transmit information in detonation of power. The power of the cellular phone is crooked on and off, and the equipment alienates for a portion of the time only and then is silent for the residual part of the eruption period. The rehearsal frequency is $217 \mathrm{~Hz}$ for GSM and DCS 1800 systems and $100 \mathrm{~Hz}$ for DECT, the phantom also contains a number of higher symmetrical due to the tight pulse.

Hirata et al., (2006) discussed the correlation between peak SAR and maximum temperature increase is blood flow in tissues. Recently, the U.S. Environmental Protection Agency (EPA), established safety guidelines for RF exposure mobile phones in the United States. Specific Absorption Rate, or "SAR, is the gauge of the average of absorption of RF energy in the human head. The Federal Communications Commission has determine the Specific Absorption Rate of handheld mobile phones limit by 1.6 watts per kilogram, rated over one gram of tissue. However, the SAR value may vary from call to call, depending on factors such as proximity to a cell site, the proximity of the phone to the body while in use, and the use of hands-free devices [9].

The specific absorption rate (SAR) is defined by:

$\mathrm{SAR}=\sigma\left|\mathrm{E}_{\mathrm{rms}}\right|^{2} / \rho \quad \mathrm{w} / \mathrm{kg}$

$\rho \quad$ is the mass density (kilogram per meters square)

$\sigma \quad$ is the conductivity (Siemens per meter)

$\mathrm{E}_{\mathrm{rms}}$ is the root mean square value of the electrical field (volts per meter)

The threshold level is a Specific Absorption Rate value for the whole body of 4 watts per kilogram $(4 \mathrm{~W} / \mathrm{kg})$. For hand-held radiotelephones used in occupational situations, ICNIRP recommends that the localized SAR in the head be limited to $10 \mathrm{~W} / \mathrm{kg}$ averaged over any $10 \mathrm{~g}$ mass of tissue in the head ( $0.1 \mathrm{~W}$ absorbed in any $10 \mathrm{~g}$ mass of tissue in the head).

SAR is used everywhere as a globally accepted safety measure. Used as guidelines for the maximum energy absorbed by a unit of mass to exposed tissue of a person using a cell phone, over a given time or more simply the power absorbed per unit mass. SAR levels are usually expressed in units of watts per kilogram $(\mathrm{W} / \mathrm{kg})$ in $1 \mathrm{~g}$ of tissue, except in Europe its $10 \mathrm{~g}$ of tissue.

The exposure to ionizing radiation can cause earnest biological damage. This procedure can produce molecular changes that can lead to damage in biological tissue, including the production of cancer. This procedure requires interaction with high levels of electromagnetic energy. Those kinds of electromagnetic radiation with enough energy to ionize biological material include gamma and X-radiation radiation. The energy levels associated with RF and microwave radiation, on the other hand, are not great enough to cause the ionization of atoms and molecules and RF energy is, therefore, is a type of non-ionizing radiation.

However, radiofrequency energy can produce other types of biological effects, such as, thermal effects, which can cause tissue damage due to the heating effect by increasing body temperature. Mobile phones are designed to operate at power levels below the threshold for known thermal effects. Radio frequency (RF) radiation could produce other effects. 
Also, other potential biological effects are associated with cell membranes and the movement of currents through the membrane in either direction. However, membranes are far-famed to have strongly nonlinear electric properties (Montaigne and Pickard, 1984). When a voltage is applied across the membrane, the current that flows is not always proportional to the voltage. Part of this no linearity may, in fact, be due to the effect of the electric field on the proteins in the membrane or nearby, which assist the flow of the product currents through the membrane.

A radio can reveal and dilate an exceedingly small signal against a background of very much larger signals. The resonant circuit basically responds only to electromagnetic waves of frequencies within a narrow bandwidth. The power required to enlarge these waves comes from the power supply of the radio.

Table 1. SAR Guidelines From Around the World

\begin{tabular}{|l|l|l|l|}
\hline Region & $\begin{array}{l}\text { Reference to SAR } \\
\text { measurement }\end{array}$ & Reference to SAR limit & SAR Limit \\
\hline United States & $\begin{array}{l}\text { Federal Comm. } \\
\text { Commission Guidelines } \\
\text { (FCC 1997) }\end{array}$ & $\begin{array}{l}\text { American Standard } \\
\text { ANSI C95.1 } \\
\text { (ANSI1992) }\end{array}$ & $\begin{array}{l}1.6 \mathrm{~W} / \mathrm{Kg} \text { in 1g of } \\
\text { tissue }\end{array}$ \\
\hline Europe & $\begin{array}{l}\text { European Spec. } \\
\text { ES 59005 (1998) }\end{array}$ & $\begin{array}{l}\text { ICNIRP Guidelines } \\
1998 \text { (ICNIRP 1998) }\end{array}$ & $\begin{array}{l}2.0 \mathrm{~W} / \mathrm{Kg} \text { in 10g } \\
\text { of tissue }\end{array}$ \\
\hline
\end{tabular}

\section{RELATED WORK}

Recently evidence has been reported about the possible health effects such as; brain tumor, bloodbrain barrier (BBB) permeability function, sleep problems, cognitive function, DNA damage, immunity system function, stress reaction, and increased incidence rate of traffic accidents due to using mobile phone during driving. Recently, many studies have concerns about the association between exposure to EMF radiation and the risk of cancer. Some studies reported association between cancer and the use of some appliances, such as television sets, hair dryers, radio and television transmitters, TV towers, and electric razors.

One of the important reasons for the work presented in this paper is to answer the question of whether the use of cell phone is harmful for users or not. However, the review presented in this paper has not entirely answered the question. More long term studies are needed. What we could conclude is that heavy cell phone could be under high risk of negative effects due to the exposure of EMF radiation. This conclusion indicate that caution is needed when using cell phones and more research is necessary for risk assessment based on higher number of long-term users.

Other studies has concerns regarding human health effects due to exposure to EMF radiation, such as mobile phones as in Hardell et al. 1999; Muscat et al. 2000; Inskip et al. 2001; Johansen et al. 2001; and Rothman et al. 1996. Several studies have linked exposure to extremely low frequency electromagnetic fields (ELF-EMF) and increase the risk of childhood leukemia as in Ahlbom et al., 2000; Deadman et al. 1999; Foliart et al. 2002; and Foliart et al. 2001. 
Advanced Computing : An International Journal (ACIJ), Vol.5, No.5/6, November 2014

\section{METHOD AND ANALYSIS}

The FDTD method is the most demotic numerical method for the solution of problems in electromagnetics. Although the finite-difference time-domain method has dwell for over thirty years, its saleability continues to grow as computing costs perpetuate to descend. Moreover, expansions and consolidations to the method are continually being published which further broaden its renewal. Because of the enormous amount of finite-difference time-domain-related research activity, tracking the finite-difference time-domain propriety can be a disconcerting task.

The finite-difference time-domain method proposed by Yee in 1966, represent a simple and splendid way to prudent the differential form of Maxwell's equations. Yee method have been used an electric field (E) grid which was offset both spatially and temporally from a magnetic field $(\mathrm{H})$ grid to obtain update equations that yield the present fields throughout the computational domain in terms of the past fields.

The finite-difference time-domain method can be used to calculate either dispersed fields or total fields. For the total fields, it often calculated only over an inner subsection of the computational range $[14,15,16]$, while dispersed fields are calculated in the remaining portion of the grid.

\subsection{The Yee Method}

The finite-difference time-domain method for the Maxwell equations was introduced by K. S. Yee. The method uses a Leapfrog scheme on staggered Cartesian grids. Therefore, some artificial boundary conditions (ABC) is needed to truncate the computational domain. A more modern approach is to use the Perfectly Matched Layer (PML) introduced by Berenger in 1994.

The Yee method has several advantages. It is durable and easy to understand. Moreover, it is possible to ascertain the response in a selected frequency band in one calculation by using a pulse aggravation. This cannot be achieved with a frequency domain method. Furthermore, the absence of a general sub gridding scheme means that structures smaller than the resolution have to be treated by sub cell models.

Therefore the sub cell models have to be improved and new sub cell models must be developed [21]. Numerical computation is accomplished by applying some excitation to an object or group of objects in a 3-dimensional space and calculating the fields as time progresses.

The FDTD method has many capabilities which are useful in analysis, modelling and design of anything interacting with electromagnetic radiation. Some capabilities of the FDTD method include : Arbitrary structures of complex compositions can be modelled Interaction with complex, lossy, lossless and perfectly conducting bodies Dielectrics materials, lossless and lossy Magnetic materials, lossless and lossy Anisotropic materials such as plasmas. Transmission line structures Micro strip transmission line, Co-Planar Waveguide (CPW), and Coaxial can all be accurately modelled.

Interaction with active devices and circuit simulations Inductors, Capacitors and Resistors can be included Advice devices such as diodes, diodes and transistors can be modelled Circuit 
parameters such as crosstalk, and via holes are useful in design and analysis of compact, high speed digital circuit boards.

Antenna structures can be accurately characterized S Parameters, Impedance, Radiation Efficiency Far-field radiation patterns can be calculated from the near-fields. The equations are explicit, and are only dependent on the electric / magnetic fields.

\subsection{Simulation region}

The simulation region must be divided into "Yee Cells" in order for the FDTD method to be applied. In the Cartesian coordinate system, each Yee cell contains six field components, Ex, Ey, Ez, Hx, Hy and Hz. The fields are all offset by half a space step as shown in Fig. 2 [21]:

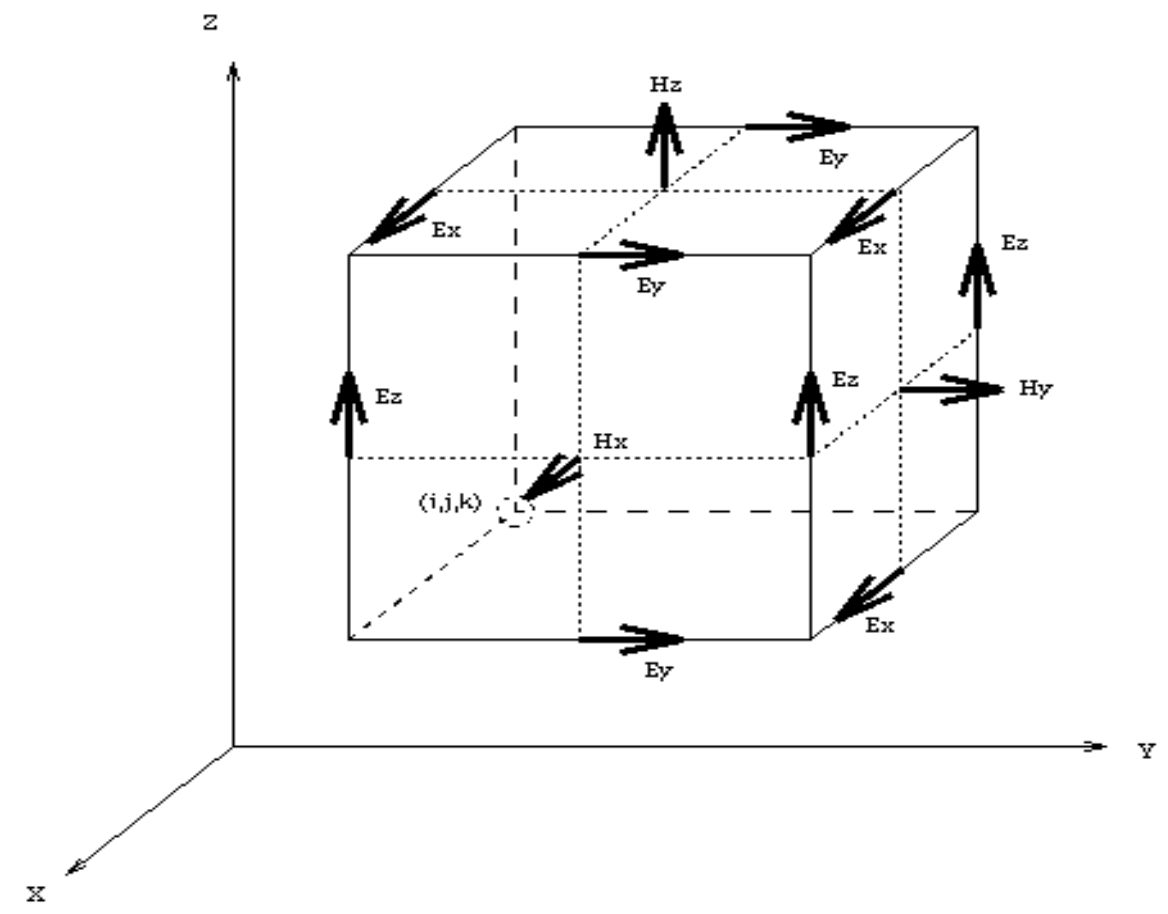

Figure 2, Standard Yee Cell

\subsection{Object Definition}

The object to be simulated is constructed of a 2 or 3 dimensional grid of Yee cells, depending on the solution required. Each field component in the simulation region is defined to consist of a different material.

\section{MODELING AND RESUltS}

In the head model, 6 tissues (see table 1). The transmitted power by the mobile phone was assumed to be 0.6 watts at a frequency of $900 \mathrm{MHz}$. The human head was simulated by 140, 4928 cells, with cell size of $2.15 \mathrm{~mm}$, mesh size of 17576 , mesh dimension of $26 \times 26 \times 26$. 
Advanced Computing : An International Journal (ACIJ), Vol.5, No.5/6, November 2014

Table 1, The head tissue properties at $900 \mathrm{MHz}$ [6], [7].

\begin{tabular}{|l|l|l|l|}
\hline Tissue & $\begin{array}{l}\text { Permittivity } \\
(\varepsilon)\end{array}$ & $\begin{array}{l}\text { Conductivity } \\
(\sigma) \mathrm{sm}^{-1}\end{array}$ & $\begin{array}{l}\text { Mass Density }(\rho) \\
\mathrm{Kg} \mathrm{cm}^{-3}\end{array}$ \\
\hline Pineal gland & 44.5 & 0.80 & 1.05 \\
\hline Brain & 45.8 & 1.24 & 1.03 \\
\hline Bone & 8.0 & 0.11 & 1.85 \\
\hline Skin & 32.0 & 0.60 & 1.10 \\
\hline Muscle & 58.5 & 1.21 & 1.04 \\
\hline Eye lens & 44.5 & 0.80 & 1.05 \\
\hline
\end{tabular}

(Assume that pineal gland has the same properties as eye lens, it is made of the same tissue as the eyes).

Time step $=3.586 \mathrm{E}^{-12}$

The number of time steps for 1 run $=50,000$ time steps

The CPU time $=23555$ seconds, wall time $=24566$ seconds

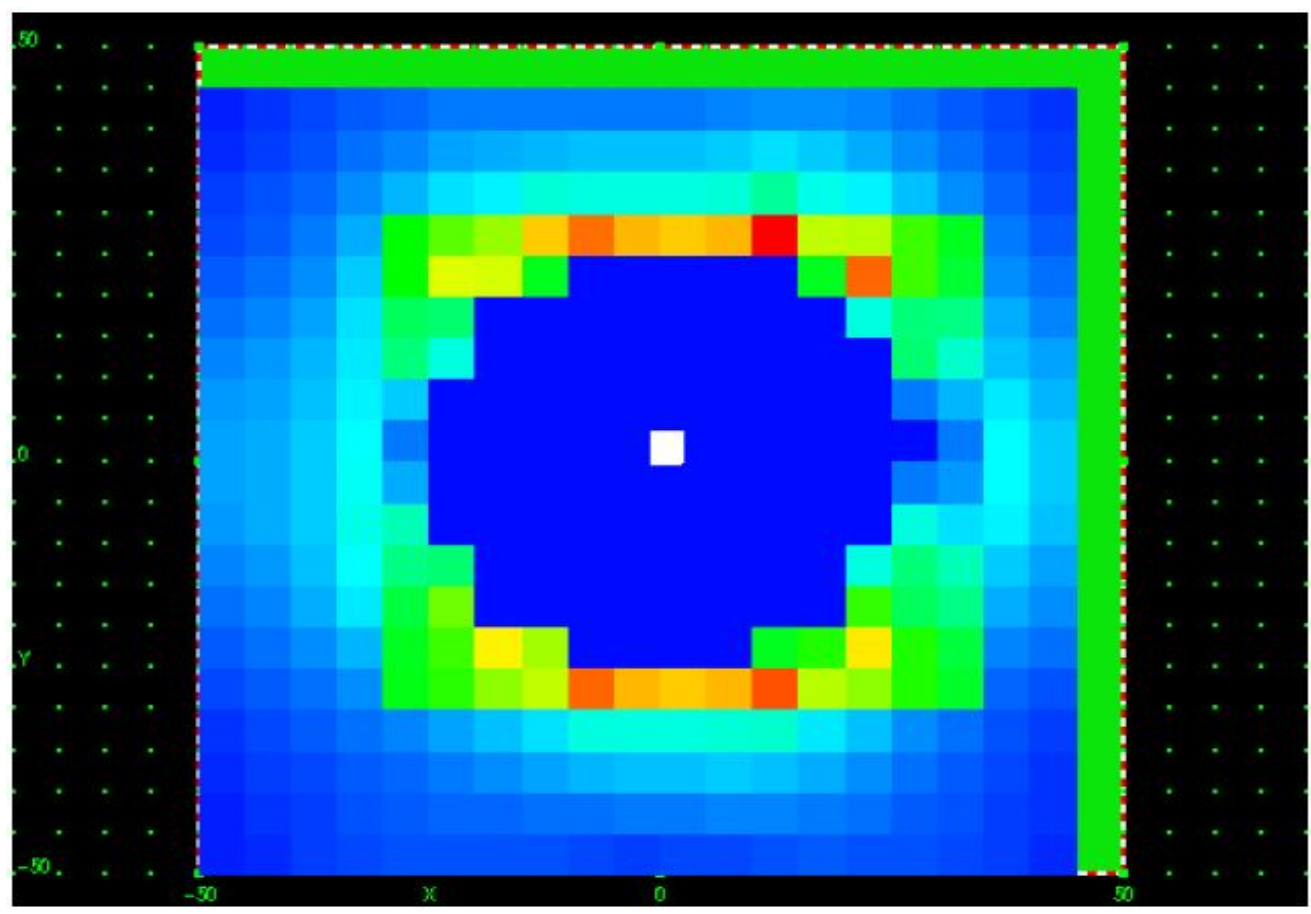




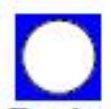

Brain

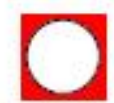

Eye lens

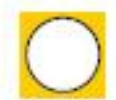

Muscle

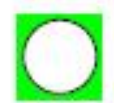

Skin

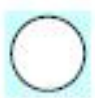

Bone

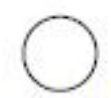

Pineal gland

Fig.3, The head cubic cells structure.

The simulation is done and the waveforms look as shown in figure (1) and figure (2). Actually the 5000 time steps would have been sufficient since there was not a large transient signal that needed to ring out. Thus the head could be considered a very low Q cavity, meaning it would have very short ring-out times. Attached are some plots of two of the signals. We have shown the transient part of the signal that exist for only a short portion of the signal an then it goes quickly to steady state. Note that in figure (1), that the mean signal amplitude is higher than that of probe6 shown in figure (2) (which is further inside the head).

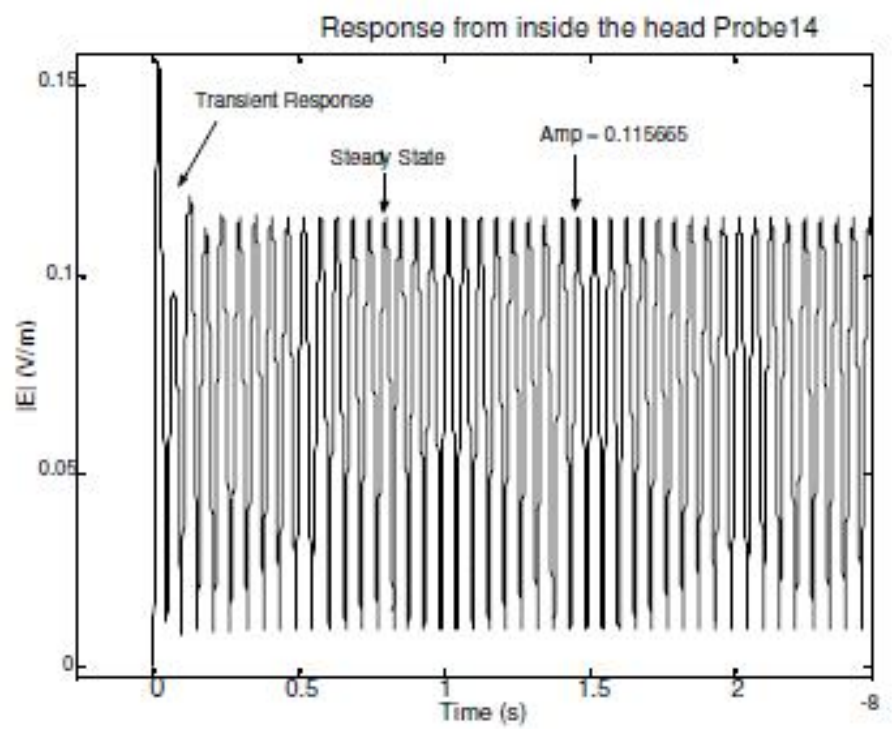

Figure 4: Probe 14's response to a external Sinusoidal signal

It is this steady state amplitude that you are after since it shows that amplitude of the standing wave at that point in the head once the system has gone to steady state. If you were to look at the spectral power density (or the FFT ) of this signal, it would be a spike cantered about $900 \mathrm{Mhz}$ with $E$ amplitude such that $E_{0}={ }^{q}\left|E_{a m p}\right|$ where $\left|E_{\text {amp }}\right|$ is the value we have pointed out on the graph in figure (1). Since your S.A.R is related to the $\left|E_{o}\right|^{2}$ then this would be from as in equation (2). where $E_{\text {amp }}$ simply the max amplitude during steady state of the signal, like that value pointed out in Figure (1). Below is a plot of a probe further inside the head where the amplitude is expected to be less than that at the surface of the head like that of Probe 14 which is located in the bone layer next to the excitation. The max amplitude in this region appears to be $\mathrm{E}_{\mathrm{amp}}=.904$ 
Advanced Computing : An International Journal (ACIJ), Vol.5, No.5/6, November 2014

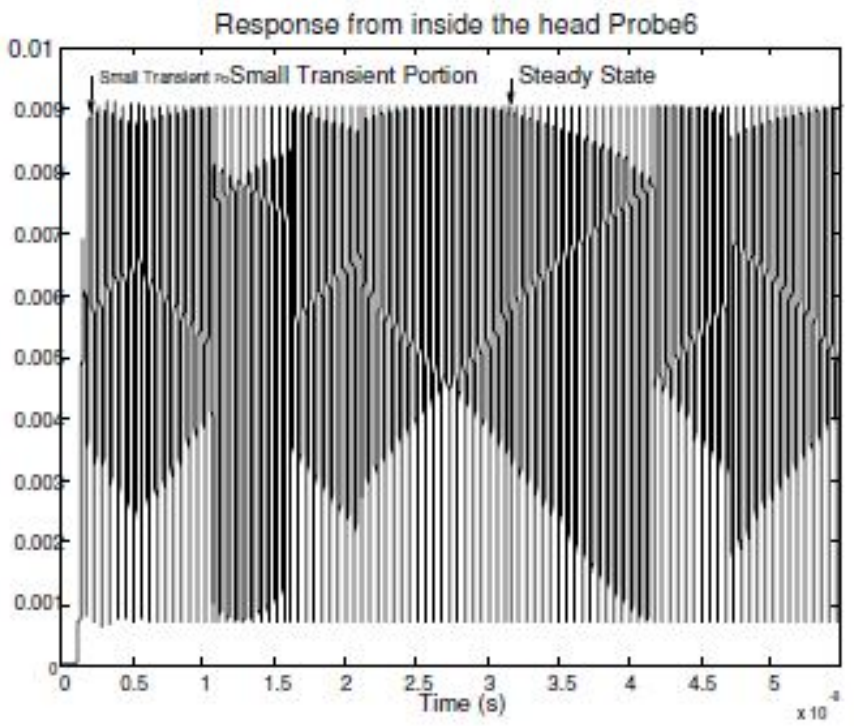

Figure 5: Probe 6's response to a external Sinusoidal signal Deep inside head

Fig. (4) and (5), shows the transient part of the signal that exist for only a short portion of the signal and then it goes quickly to steady state. Fig. (4), represent probe (14), which represent the signal in the bone tissue. Fig. (5), represent probe 6, which represent the signal in the brain tissue.

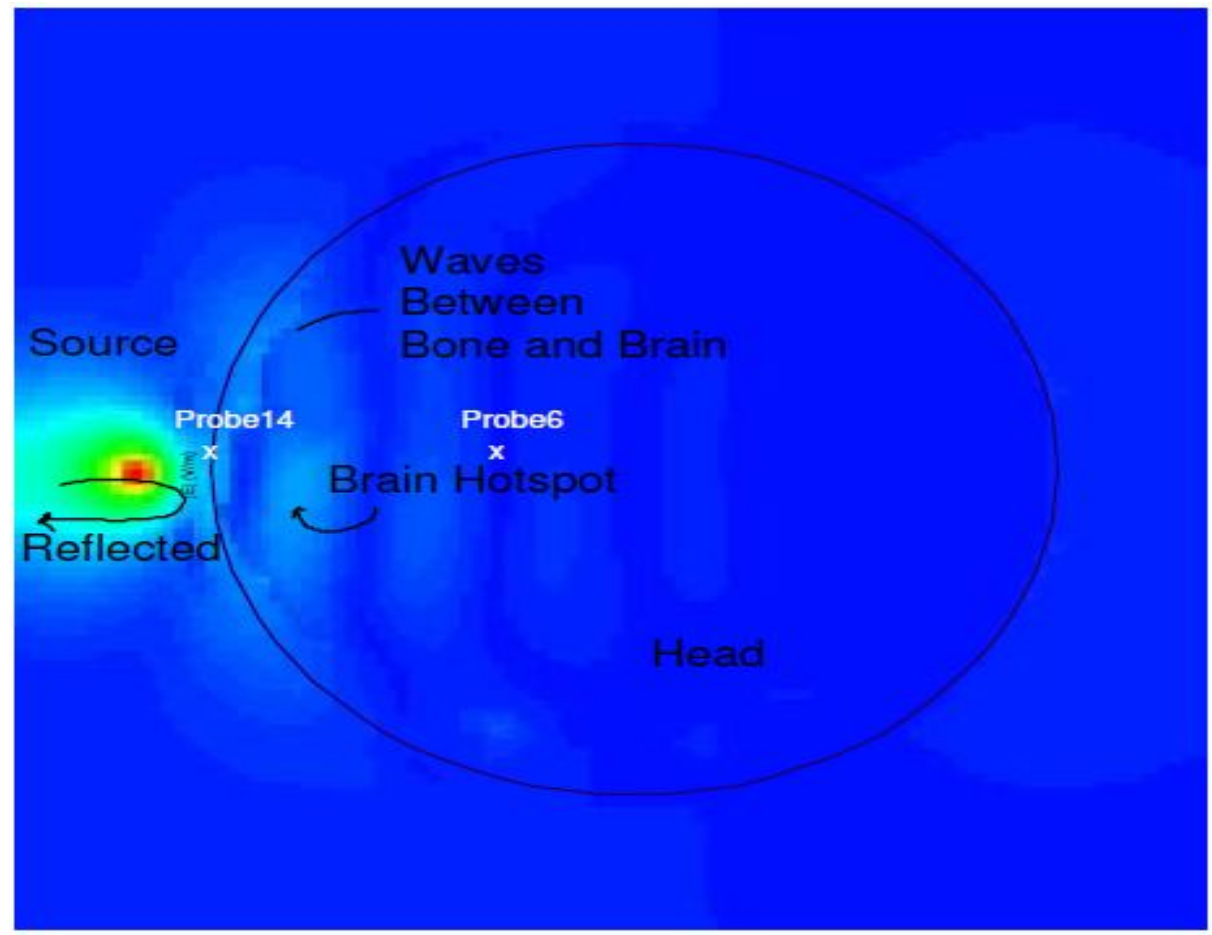

Figure 6: Look at the Electric Field Density inside Head at Steady State (15000 TS) 


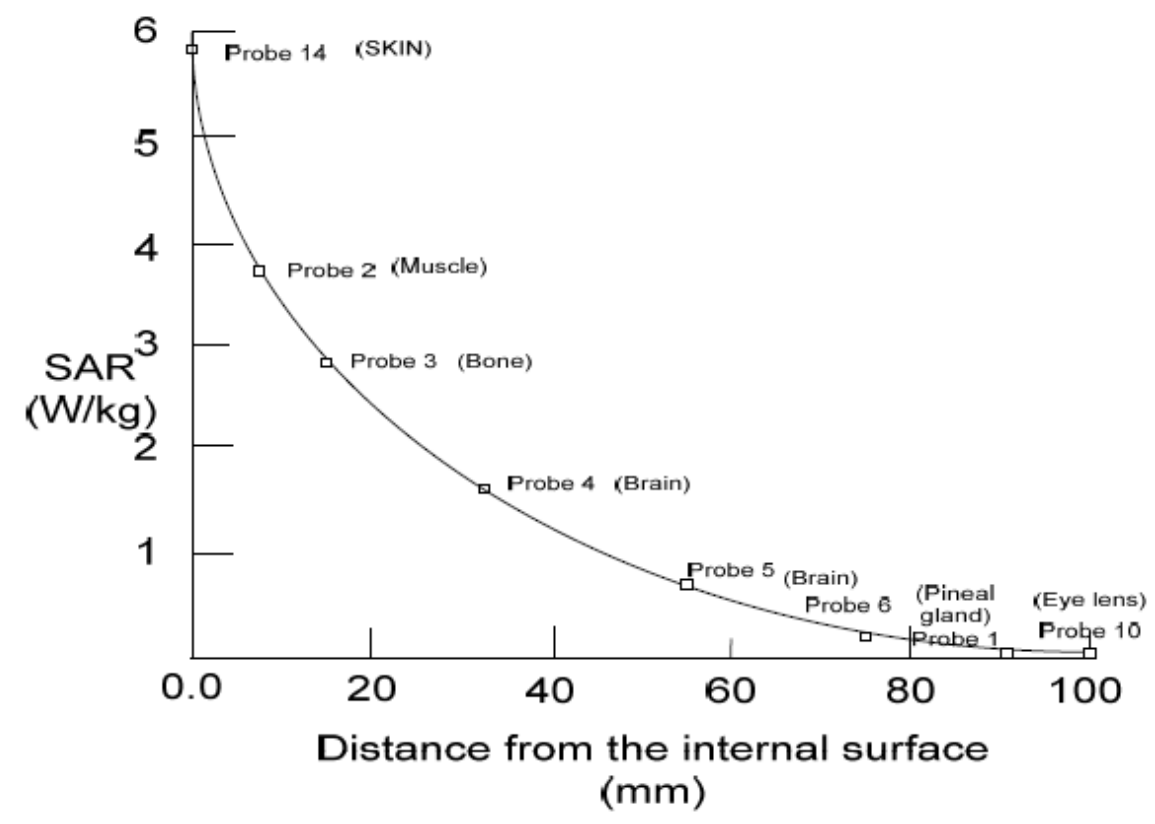

Fig. 7, shows the computed SAR.

Fig. (4), shows the mean signal amplitude is higher than that of probe (6), as shown in Fig. (5) (which is further inside the head). It is the steady state amplitude of the standing wave at that point in the head once the system has gone to steady state. That means SAR distribution in the head decreases with the distance from the radiating source, which indicate that the field strength will decaying as we go deeper in the head.

SAR is a measure of the power absorbed per unit mass of the head tissue.

$\mathrm{SAR}=\sigma\left|\mathrm{E}_{\mathrm{rms}}\right|^{2} / \rho$. Computed SAR (for $0.6 \mathrm{w}$ ) over $10 \mathrm{gm}$ of tissue.

$$
S A R \approx \frac{\left|E_{o}\right|^{2}}{\rho}=\frac{{ }^{q}\left|E_{\text {amp }}\right|^{2}}{\rho}=\frac{\left|E_{\text {amp }}\right|}{\rho}
$$

The E- field probe is proportional to the square of the internal electric field, that means, the SAR is proportional to the voltage output of the E-field probe. Fig. (7), shows the computed SAR at different points inside the head due to a radiated power of $0.6 \mathrm{~W}$.

\section{CONCLUSION}

After the increase in the use of mobile phones in the recent years, concerns have been raised about the biological effect of the exposure to the mobile phones radiofrequency electromagnetic radiation. The finite-difference time-domain method is the most demotic numerical method for the solution of problems in electromagnetic. In this paper, FDTD techniques have been used to calculate the SAR generated by a mobile phone at $900 \mathrm{MHz}$. We used the numerical technique to obtain the SAR induced at different points inside the head model. It was found that the SAR 
induced in the head, decreases with the distance from the radiating source. Which indicate that the field strength will decay as we go deeper in the head.

This analysis and the results can be used during the design process for the new mobile phones, and also help for determining the biological effects due to exposure to the electromagnetic waves irradiated from the mobile phone.

\section{REFERENCES}

[1] Mushtaq, A. Bhat., and Vijay, K., (2013) "Calculation of SAR and Measurement of Temperature Change of Human Head Due To The Mobile Phone Waves At Frequencies 900 MHz and 1800 MHz", Advances in Physics Theories and Applications, Vol.16, ISSN 2225-0638.

[2] Adheed, H. S., (2012) "A Theoretical Approach for SAR Calculation in Human Head Exposed to RF Signals", Journal of Engineering and Development, Vol. 16, No.4, ISSN 1813- 7822304.

[3] Luan, A., Mimoza, I., and Enver, H., (2010) "Computation of SAR Distribution in a Human Exposed to Mobile Phone Electromagnetic Fields", PIERS Proceedings, Xi'an, China, 22-26.

[4] Hardell, L., Carlberg, M., Hansson, K. (2011) "Pooled of case - control studies on malignant brain tumours and the use of mobile and cordless phones including living and deceased subjects". International Journal of Oncology, 38(5):1465-1474.

[5] Adair, E., Kelleher, R., Mack, W., Morocco, S. (1998) "Thermophysiological responses of human volunteers during controlled whole - body radio frequency exposure at $450 \mathrm{MHz}$. Bio electro magnetics, 19:232-245.

[6] Schwan, H.P., (1985) "Biophysical principles of the interaction of ELF fields with living matter". Publ. Plenum Press, New York.

[7] Montaigne, K., and Pickard, F., (2005) "Offset of the vacuolar potential of Characean cells in response to electromagnetic radiation over the range $250 \mathrm{~Hz}-250 \mathrm{kHz}$, Bioelectromagnetics, Volume 5, Issue 1, pages 31-38.

[8] Foster, K. R. (2000) "Thermal and Nonthermal Mechanisms of Interaction of Radio- Frequency Energy with Biological Systems", IEEE Trans Plasm Sci 28:15-17.

[9] Frohlich, K., Nancy, R., Richmond, C. (2006) "Health disparities in Canada today: Some evidenceand a theoretical framework", Health Policy, 79 -132-143.

[10] Pokorny, P. F., Almeida, E. C., Melo, and Vaz, W. (1998), "Kinetics of Amphiphile Association with Two - Phase Lipid Bilayer Vesicles", IX Congresso Nacional de Bioquímica, P10-10. Tomar.

[11] Akleman, F., and Sevgi, L., (1998) "FDTD Analysis of human head - mobile phone interaction in terms of specific absorption rate calculations and antenna design", IEEE- APS Conference, Antennas and propagation for wireless communication, vol. 1. pp. 85- 88 .

[12] Dimbylow, J., and Gandhi, O. P. (1991) "Finite-difference time-domain calculations of SAR in a realistic heterogeneous model of the head for plane - wave exposure from $600 \mathrm{MHz}$ to $3 \mathrm{GHz}$," phys .Med . Biol., vol. 36, pp. 1075-1089.

[13] Yee, K. S. (1966) "Numerical solution of initial boundary value problems involving Maxwell's equations in isotropic media," IEEE Trans. Antennas Propagat., vol. 14, pp. 302-307.

[14] Taflove, A. (1988) "Review of the formulation and applications of the finite - difference timedomain method for numerical modeling of electromagnetic wave interactions with arbitrary structures", Wave Motion, vol. 10, no. 6, pp. 547-582.

[15] Holland, R., Simpson, L., and Kunz, K. (1980) "Finite - difference analysis of EMP coupling to lossy dielectric structures, " IEEE Trans. Electromagn. Compat, vol. EMC- 22, pp. 203-209.

[16] Merewether, D. E., Fisher, R., and Smith, F. W. (1980) "On implementing a numeric Huygen's source scheme in a finite difference program to illuminate scattering bodies," IEEE Trans. Nucl. Sci., vol. 27, pp. 1829-1833.

[17] Holland, R., and Williams, J. W. (1993) "Total - field versus scattered - field finite - difference codes: A comparative assessment," IEEE Trans. Nucl. Sci., vol. NS-30, pp. 4583-4588. 
Advanced Computing : An International Journal (ACIJ), Vol.5, No.5/6, November 2014

[18] Kunz, K. S., and Luebbers, R. J. (1993) "The Finite Difference Time Domain Method for Electromagnetics", Boca Raton, FL: CRC Press.

[19] Fang, J. (1989) "Time Domain Finite Difference Computation for Maxwell's Equations", PhD thesis, University of California at Berkeley, Berkeley, CA.

[20] Kurt, L., Shlager., and John, Schneider, B. (1998) "A Survey of the Finite - Difference TimeDomain Literature", www.fdtd.org / Bibtex-db / survey-199 -html / survey.html.

[21] Yee, The Yee Method" available at www. nada.kth.se/ ulfa/CEM.html.

[22] G. Grimes \& F. Barnes, (1973) "A technique for studying chemotaxis of leukocytes in welldefined chemotactic fields", Experimental Cell Res.,vol. 79, pp. 375-385.

[23] F. Barnes \& Y. Kwon, (2005) "A theoretical study of the effects of RF field gradients in the vicinity of membranes", J. Bioelectromagn., vol. 26, no. 2, pp. 118-124.

[24] Ashraf A. Aly, Safaai Bin Deris, Nazar Zaki, "Research Review For Digital Image Segmentation Techniques.International Journal of Computer Science \& Information Technology (IJCSIT).Vol 3, No 5, Oct 2011.

[25] Ashraf A. Aly, Safaai Bin Deris, Nazar Zaki, "The Effects on Cells Mobility Due to Exposure to EMF Radiation", Advanced Computing: An International Journal (ACIJ), Vol.2, No.4, July 2011.

[26] Ashraf A. Aly, and Frank S. Barnes, Effects of $900-\mathrm{MHz}$ Radio Frequencies on the Chemotaxis of Human Neutrophils in Vitro, IEEE Transactions On Biomedical Engineering, Vol. 55, No. 2, February 2008.

[27] Campion EW, "Power lines, Cancer, and Fear." The New England journal of medicine, 337.1: 446, 1997.

[28] Inskip PD, Tarone RE, Hatch EE, “Cellular telephone use and brain tumors,” N. Engl J Med, 344:7986, 2001. 